\title{
NEW CHALLENGES TO RENIN-ANGIOTENSIN-SYSTEM IN COVID-19 PANDEMIC
}

\author{
Stanislav Yanev* and Tsveta Stoyanova \\ Institute of Neurobiology, Department of Drug Toxicology, Bulgarian Academy of Sciences, Sofia, \\ Bulgaria
}

In the fight against the global epidemic from the new corona virus (SARS-CoV-2), awareness on the site of the primary viral attack, the so-called „entry port" enables an implies efficient prophylactic/therapeutic approach. The attack is aimed at the important balancing unit of the renin-angiotensin system (RAS), angiotensin-converting enzyme 2 (ACE2), which regulates the level of angiotensin II (Ang II). While Ang II has vasoconstrictor and inflammatory functions, the ACE2 converted product of Ang-(1-7) possesses vasodilating and anti-inflammatory functions. In patients with pathological cardiovascular symptoms and increased blood pressure, maintenance of optimal Ang II is achieved by inhibiting the synthesizing enzyme ACE1 or blocking the angiotensin receptor response (ATR). In this Dance Round, an attempt is made to address the question: In the unbalanced functions of RAS (manifesting as an outcome of SARS-CoV-2 epidemic), will the therapeutic effect of ACE1 inhibitors change and in what direction? Biomed Rev 2020; 31: 105-112

Keywords: angiotensin, angiotensin-converting enzyme, ACE inhibitors, SARS-CoV-2, COVID-19

\section{INTRODUCTION}

We live in a time of respiratory infection epidemic caused by a new representative of the Corona virus family - SARSCoV-2. Scientists of diverse expertise around the world have made extraordinary efforts to obtain as much information about the virus as is possible: its nature, path of spread, and the major goal naturally, was to understand the "front door" for the viral attack to organism. That is, how does the virus enter our body? The answer to this turned out to be a protein found in our cells, abbreviated as ACE2 (angiotensin-converting enzyme 2), which also serves as the entry portal for another coronavirus (SARS-CoV) (1). ACE2 is an important enzyme involved in the functioning of a chain of peptides, within the renin-angiotensin-system (RAS) (Fig. 1). It is very crucial to cardiac health, fluid and salt homeostasis. This issue assumes high relevance with the mass, as co-morbidities are associated

*Correspondence to: Dr Stanislav Yanev, Institute of Neurobiology, Department of Drug Toxicology, Bulgarian Academy of Sciences, BG-1113 Sofia, Bulgaria

E-mail: YanevSG@gmail.com 
with Coronavirus infections. Several patients routinely use inhibitors of ACE1, an enzyme with quite distinct functions from ACE2 (2). Naturally, commoners and experts alike are intrigued at what direction this therapeutic approach will change the ACE1/ACE2 balance, which is compromised in the context of viral infection (3).

A brief description of the RAS system would allow us to understand the consequences of the viral hijack of the physiological processes better. Renin cleaves a decapeptide, angiotensin I (Ang I), from renin's substrate (Angiotensinogen). Ang I has little or no biological activity and is a substrate for several plasma peptidases; one of which is ACE1, a dipeptidyl carboxypeptidase. This forms the octapeptide angiotensin II (Ang II) from angiotensin I. By activating the angiotensin receptor (AT1R), Ang II serves as the main trigger leading to vasoconstriction, fibrosis, inflammation and altered redox balance. Further, ACE2 shortens Ang II peptide to Ang-(1-7). Ang-(1-7) is an agonist at both AT2R receptors and its own
G-protein coupled receptor, Mas. That activation elicits quite distinct responses, such as vasodilatation, anti-inflammatory and anti-fibrotic activity.

At first glance, it is clear that the SARS-CoV-2 viral attack would disturb the "homeostasis" of the RAS, i.e. the balance between ACE1/Ang II/AT1R axis and ACE2/Ang-(1-7)/Mas axis.

In the present Dance Round, we would like to (i) describe the main players in the RAS (ACE1 and ACE2), (ii) specify their altered functions for cardiovascular and reproductive systems in the context of COVID-19 epidemic, and (iii) answer whether the effects and responses to ACE1 inhibitors (ACE-I) change under these conditions.

\section{ANGIOTENSIN-I CONVERTING ENZYME, FUNCTIONS}

Angiotensin-I converting enzyme (ACE, dipeptidyl carboxypeptidase I, kininase II, EC 3.4.15.1) is a membranebound zinc-containing multifunctional enzyme. Although

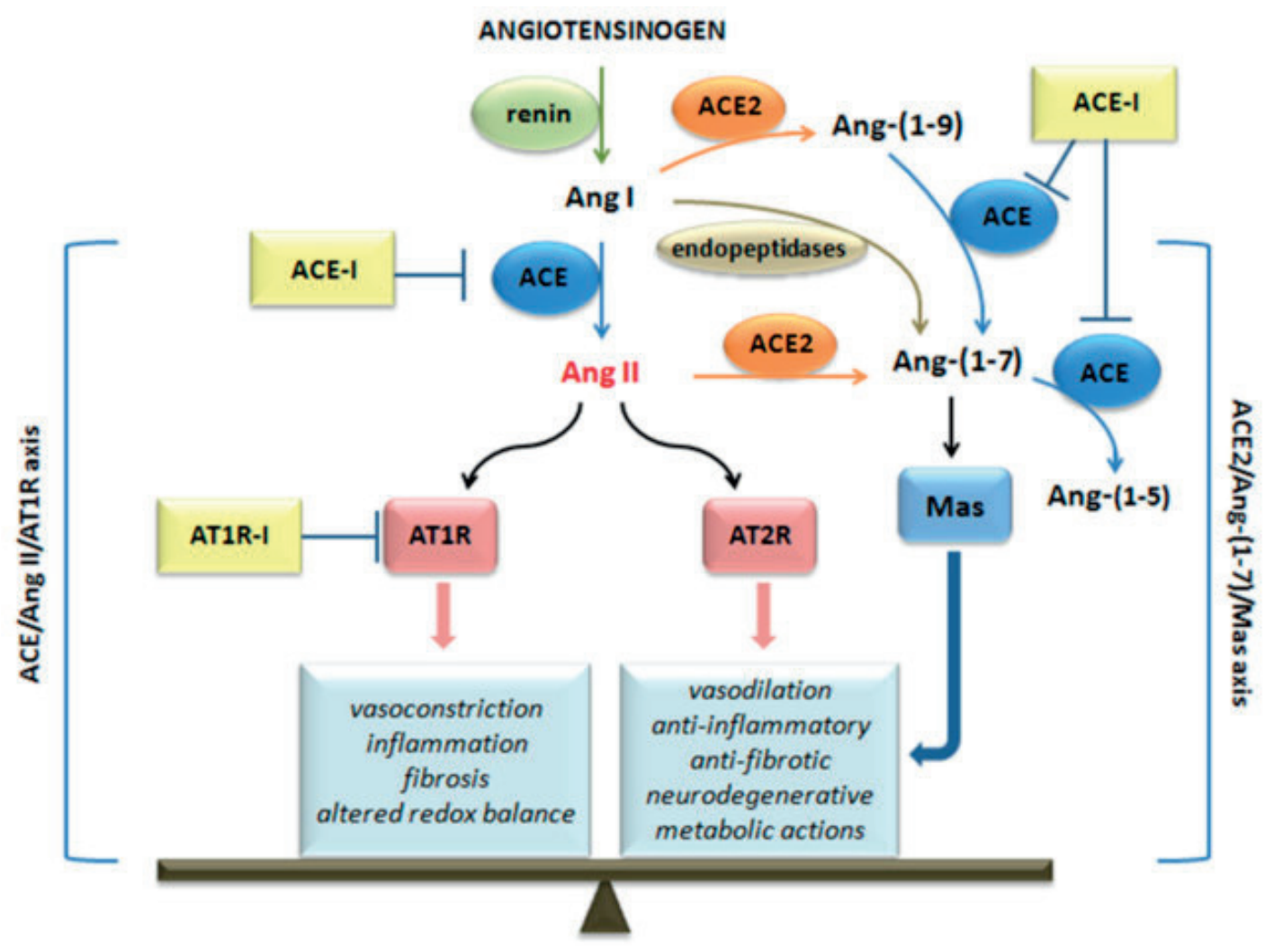

Figure 1. The renin-angiotensin system (RAS) cascade and angiotensin-converting enzyme (ACE) and angiotensin receptor 1 (AT1R) inhibitors action. Ang I: angiotensin I; Ang II: angiotensin II; ACE: angiotensin-converting enzyme; ACE2: angiotensinconverting enzyme 2; ATR1: angiotensin II receptor type 1; ATR2: angiotensin II receptor type 2; ACE-I: ACE inhibitors; AT1R-I: angiotensin receptor $1 . \rightarrow$ transformation; † inhibition; $\Rightarrow$ effects mediated. From: D. D’Ardes et al., COVID-19 and RAS: Unravelling and Unclear Relationship, Int J Mol Sci 2020; 21(8): 3003 
known for more than 50 years, only in the last decade the wide range of its physiological functions were unraveled.

In addition to the so-called somatic form (sACE) ACE1 (which consists of two homologous with independent catalytic structures, C-domain and the N-domain, of different biological functions (Fig. 2), two more forms have been discovered. The testicular form of the enzyme (tACE) consists of a C-domain and ACE2 moncarboxypeptidase isozyme that possesses one catalytic center and is not sensitive to inhibitors of ACE1 (4).

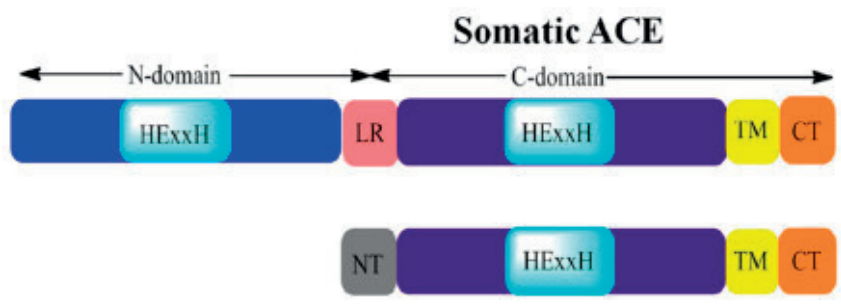

Testis ACE

Figure 2. Schematic representation of the structural motifs of somatic ( $A A C E$ ) and testicular form ( $A C E$ ) of ACE. Shown is the zinc binding motif illustrated with HExxH, present in both forms. From: Harrison, C., and Acharya, K.R. ACE for all - a molecular perspective. J Cell Commun Signal 2014; 8:195-210

Drugs widely used in medical practice, such as captopril, enalaprilat, trandolaprilat lisinopril etc., which act as competitive inhibitors of ACE1, show a different affinity for both catalytic centers. It was reported that trandoprilat binds best with C-domain, followed by lisinopril, enaprilat, captopril (5). In contrast, the N-domain activity is in the order trandoprilat $>$ captopril $>$ enaprilat $>$ lisinopril. These results show that selectivity of inhibition against both domains strongly depends on the structure of the inhibitor.

Besides participating in the regulation of the waterelectrolyte balance (6) and systemic vascular resistance and blood pressure, renin-angiotensin system participates in functional modulation of many cellular systems and organs as the cognition processes (7), regulation of duodenal mucosa bicarbonate secretion (8), cellular differentiation and apoptosis (9), the inflammation processes (10) and male reproductive seminal function (11). It is interesting to mention the organ distribution of ACE1 activity in one of the most studied experimental animals, the rat. High specific activities of converting enzyme were found in lung and in segments of the digestive tract, but the highest activities were in testis and epididymis, associated with tubular fluids, but not in sperm cells (12).

Over the past decade, the interest in biologically active peptides as potential therapeutic agents constantly increased due to diversity in their biological activity and significantly lower toxicity of the peptides and their breakdown products. An advantage of biologically active peptides is that they very rarely interact with other drug substances. The use of a specific peptide drugs is a potential alternative therapy for the treatment of hypertension (13). Along with this, an increased interest in foods and dietary supplements enriched with peptides with anti-hypertensive action.

Modern research is aimed to introduce new biochemical tests with the application of selective substrates to distinguish the activity of different ACE1 isoenzyme forms and clarification of their physiological functions. The results of these studies would substantially assist the search for new selective inhibitors with more effective structures (for the different ACE1 isoforms), such as- peptides, peptidomimetics, anthocyanins, flavonols and triterpenes.

\section{ANGIOTENSIN CONVERTING ENZYME 2 (ACE2)}

TheACE2, a single pass type 1 membranemonocarboxypeptidase, discovered 2 decades ago, consists of an $\mathrm{N}$-terminal peptidase domain and C-terminal collectrin like domain $(2,14)$. It is the peptidase domain that is responsible for the main functions of RAS. The ACE2 shares $40 \%$ homology with the N-terminal catalytic domain of ACE1, and a hydrophobic region near the $\mathrm{C}$-terminus likely to serve as a membrane anchor. The ACE2 protein is encoded by the ACE2 gene located on chromosome $\mathrm{Xp} 22$. These ACE2 proteins are more abundantly expressed on the apical surface of the well-differentiated and mostly ciliated airway epithelium of the lungs (alveolar Type- 2 cells), and enterocytes of the small intestine. Furthermore, ACE2 protein is expressed in arterial and venous endothelial cells and arterial smooth muscle cells, in the heart, kidneys, adrenal glands, pancreas, skeletal muscle, and adipose tissues.

ACE1 inhibitors (captopril, enalaprilat, lisinopril), widely used as drugs to regulate the level of angiotensin II and vascular tone, bind to the catalytic center of ACE2, without inhibiting it. It would be important to show whether these enzyme inhibitors can indirectly alter the conformation at the site of virus binding (RBD) and thus affect ACE2's interaction with the virus. It is certainly useful to test these drugs for their ability to block RBD-ACE2 interaction (15).

Data on influencing the functions of ACE2 in the body by 
different xenobiotics are still insufficient. Some examples could be listed in this direction as:

Reducing the expression of ACE2 (from databases analysis (16):

(i) Connectivity Map (CMap) - Azathioprine

(ii) JeaMoon Map (JMap) (traditional Chinese medicine): Andrographis, Urtica, Sambucus, Astragalus, valproic acid, butyrate, and epoxomicin

ACE2 activators:

(i) xanthenone (XNT): Chronic XNT administration improves the endothelial function of hypertensive and diabetic rat vessels by attenuation of the oxidative stress (17).

(ii) resorcinolnaphthalein, a yellow dye (18)

(iii) diminazene aceturate (an antitrypanosomal drug) (19). ACE2 inhibitors:

(i) DX600 (has $\mathrm{K}_{\mathrm{i}}$ of $2.8 \mathrm{nM}$ ) is selective inhibitor. It is not hydrolyzed by ACE2 and it does not inhibit ACE activity (20).

\section{ACE1, ACE2 AND SARS-COV-2}

The coronavirus SARS-CoV-2, a single stranded RNA virus, has been seen to infect humans through their envelope spike glycoprotein (S-protein), which is responsible for CoV cell entry and host-to-host transmission. During viral infection, this S-protein cleaves into two fragments, S1 and S2. The FURIN cleavage site in the SARS-CoV-2S protein may provide a priming mechanism. The ectodomain $\mathrm{S} 1$ binds to the peptidase domain of the ACE2 enzyme, while S2 is cleaved further by the host cell serine protease TMPRSS2, resulting in membrane fusion. Both these steps are essential for the viral entry into cells.

\section{Cardiovascular disease patients under ACE1 and ARBS blockers therapy}

SARS-CoV-2 attacks any cell type in the body expressing ACE2.

What should the common people and the professionals be concerned about this fact, in the context of COVID-19 pandemic? (21). Extensive worldwide meta-analysis studies show that high blood pressure patients pose a higher risk to get afflicted with COVID-19, and are likely to have worse symptoms and to mortality rates.

The logical questions that follow are: Is this increased risk due to changes in health status of such patients (weaker immune system) or is it due to the fact that they take medicines such as ACE1 inhibitors or angiotensin receptor blockers (ARBS)?

What are the evidence for beneficial or harmful effects of modulation of RAS by ACE1 inhibitors for the development and outcome of COVID-19 pneumonia?

It could be assumed that increased numbers of ACE2 receptors throughout their cardiopulmonary circulations may be the cause of the increased risk to get corona virus when taking ACE1 inhibitors or ARBS inhibitors. Indications to such effects were observed in experimental animal models (22).

The crucial evidence points towards the protective role of ACE1 inhibitors (but not ARBs) in patients subject to the risk of pneumonia. Patient populations that may benefit most are those with a history of stroke (23). ACE1 inhibitors were also associated with a decrease in pneumonia-related mortality (24). It is important to mention that the risk of pneumonia is reduced by about a third if ACE1 inhibitors are used for hypertension, as compared to the use of other antihypertensive drugs in patients with a history of stroke incidents (25).

Extensive meta-analysis enrolling 9890 hypertensive subjects strongly supports the recommendation of several scientific societies to continue ARBs or ACE11 inhibitors for all patients (26). The same positive conclusion was reached in a cohort study including 8.3 million people in UK. There was no evidence for any increased or reduced risk of COVID-19 patients in intensive care unit (ICU) admission treated with ACE1 inhibitor and ARB prescriptions (27). The same confirmative conclusions were reached by many others clinical studies (28-42).

With respect to striking an optimal balance between AT1R antagonists versus ACE1 inhibitors in patients with COVID-19, some studies stressed that it could be effective to prefer AT1R antagonists over ACE1 inhibitors in COVID-19 patients since sartans (Valsartan) maintain the function of the ACE2 enzyme, preserving the substrate Ang II, which is subject to be metabolized into Ang (1-7) (43).

Presently, all guidelines recommend continuing ACEI/ ARBs in patients diagnosed with COVID-19 infection. Recommendations are as follows (44):

(i) In non-infected patients and patients at risk, there is currently no valid reason to discontinue RAS blockade.

(ii) In healthy subjects at risk, evidence is not (yet!) sufficient to prophylactically recommend RAS blockade.

(iii) If apprehensions about increased infectivity persist, patients on ACEIs or ARBs could be switched 
temporarily to a direct renin inhibitor.

(iv) In COVID-19-positive patients on RAS blockers, the pharmacotherapy should be continued.

(v) In febrile patients with pulmonary symptoms on RAS blockers, close monitoring of blood pressure and renal function is advisable; RAS blockers should be discontinued only as clinically indicated.

\section{RAS, COVID-19 AND MALE AND FEMALE REPRODUCTION $(45,46)$}

Sperm is unique in containing the ACE C-domain isoform and in this regard, is a favorable site for testing the selectivity of inhibition of novel peptide compounds. Studying the effects of enzyme activity on human spermatozoa motility and comparing the effect of the new peptides inhibitors in this system would provide important information on the possible adverse effects of some ACE1 inhibitors used in medicinal practice. On the other hand, the activity of tACE could be proposed as a biomarker for the evaluation of the reproductive activity of human spermatozoa. A similar test was already proposed in veterinary medical practice for checking the reproductive capacity of bull spermatozoa (47).

Intra-cytoplasmic sperm injection (ICSI) is currently the primary technique used to achieve pregnancy when male infertility is a factor. Systemic clinical trials suggest that embryos with a higher implantation potential come from semen samples with higher percentages of testicular tACE-positive cells and fewer tACE enzyme molecules per spermatozoa (48).

ACE2 is regulated by a gene that is located on the $\mathrm{X}$ chromosome, thereby suggesting that some differences may exist in the expression of ACE2 in men and women. Men are more sensitive than women to coronavirus attack (49). It is suggested that this outcome is because low levels of androgens in women suppress TMPRSS2 (a serine protease) expression.

Human spermatozoa possess the entire repertoire of receptors (AT1R, AT2R, MAS) and ligand processing enzymes (ACE1 and ACE2) needed to support the angiotensin signaling cascade. The latter not only provides SARS-CoV-2 with a foothold on the sperm surface but may also promote integration, given the additional presence of a range of proteases (TMPRSS2, TMPRSS11B,TMPRSS12, furin) capable of promoting viral fusion.

What are the possible mechanisms by which corona virus affect male and female reproductive function? ACE2 receptors have recently been observed on human Leydig-Davidoff cells (50), implying a possible direct effect of the virus on the male reproductive system. ACE2 receptors have been also reported to be expressed in human ovaries (51), while angiotensin-(1-7) has been detected in measurable amounts in the follicular fluid.

\section{CONCLUSION}

Since December 2019, the epidemic of SARS-CoV-2 has stimulated scientists around the world to examine the details of virus-host interaction. This is envisaged to lead to a successful therapeutic approach that could lead to reducing the morbidity and damage from the epidemic. In the efforts to test known drugs for their efficacy in a specific antiviral action, safety of the administration of ACE1 inhibitors in subjects have been explored. Several directions are relevant:

(i) Does ACE-I interact with ACE2 as substrates or inhibitors? So far, all studies in this regard have been negative.

(ii) Does ACE-I alter the affinity of interaction of ACE2 binding site with S-protein of viral head? No information so far.

(iii) Increasing the demand for new selective inhibitors for different isoforms of ACE1, seeking to reduce adverse reactions (bradykinin induced cough; decreased male reproductive efficiency) and increase their effectiveness (higher inhibitory potency; increased oral bioavailability).

Accelerated and successful answers to these questions are possible only after the combined efforts of scientists from different fields of biology, pharmacy and medicine. The ideas and facts set out in this review reflect the efforts of such a unified scientific team.

\section{CONFLICT OF INTEREST}

The authors have no conflict of interests to declare.

\section{ACKNOWLEDGEMENT}

This review was supported by Bulgarian Scientific Fund under project CP-06-N 21/5, 2018.

\section{REFERENCES}

1. Li W, Moore MJ, Vasilieva N, Sui J, Wong SK, Berne $\mathrm{MA}$, et al. Angiotensin-converting enzyme 2 is a functional receptor for the SARS coronavirus. Nature 2003; 426(6965): 450-454. [DOI: 10.1038/nature02145]

2. Zisman LS. ACE and ACE2: a tale of two enzymes. Eur Heart J 2005; 26(4): 322-324. [DOI: 10.1093/eurheartj/ ehi043] 
3. Pagliaro P, Penna C. ACE/ACE2 Ratio: AKey Also in 2019 Coronavirus Disease (Covid-19)? Front Med (Lausanne) 2020; 7(335. [DOI: 10.3389/fmed.2020.00335]

4. Soubrier F, Alhenc-Gelas F, Hubert C, Allegrini J, et al. Two Putative Active Centers in Human Angiotensin I-Converting Enzyme Revealed by Molecular Cloning. Proc Natl Acad Sci USA 1988; 85(24): 9386-9390.

5. Wei L, Clauser E, Alhenc-Gelas F, Corvol P. The two homologous domains of human angiotensin I-converting enzyme interact differently with competitive inhibitors. J Biol Chem 1992; 267(19): 13398-13405.

6. Bernstein KE, Ong FS, Blackwell WL, Shah KH, Giani JF, Gonzalez-Villalobos RA, et al. A Modern Understanding of the Traditional and Nontraditional Biological Functions of Angiotensin-Converting Enzyme. Pharmacol Rev 2013; 65(1): 1-46.

7. Jackson L, Eldahshan W, Fagan S, Ergul A. Within the Brain: The Renin Angiotensin System. Int J Mol Sci 2018; 19(3): 876 .

8. Johansson B, Holm M, Ewert S, Casselbrant A, Pettersson A, Fändriks L. Angiotensin II type 2 receptormediated duodenal mucosal alkaline secretion in the rat. Am J Physiol-Gastroint Liver Physiol 2001; 280(6): G1254-G1260. [DOI: 10.1152/ajpgi.2001.280.6.G1254]

9. Paul M, Mehr AP, Kreutz R. Physiology of Local ReninAngiotensin Systems. Physiol Rev 2006; 86(3): 747-803. [DOI: 10.1152/physrev.00036.2005]

10. Suzuki Y, Ruiz-Ortega M, Lorenzo O, Ruperez M, Esteban V, Egido J. Inflammation and angiotensin II. Int J Biochem Cell Biol 2003; 35(6): 881-900. [DOI: 10.1016/ S1357-2725(02)00271-6]

11. Pauls K, Metzger R, Steger K, Klonisch T, Danilov S, Franke FE. Isoforms of angiotensin I-converting enzyme in the development and differentiation of human testis and epididymis. Andrologia 2003; 35(1): 32-43.

12. Cushman DW, Cheung HS. Concentrations of angiotensinconverting enzyme in tissues of the rat. Biochim Biophys Acta Enzymol 1971; 250(1): 261-265. [DOI: 10.1016/0005-2744(71)90142-2]

13. Zhou Z, Cheng C, Li Y. Structure-based design and optimization of antihypertensive peptides to obtain high inhibitory potency against both renin and angiotensin I-converting enzyme. SAR QSAR Environ Res 2015;26(12): 1001-1016. [DOI: 10.1080/1062936X.2015.1104725]

14. Guy JL, Lambert DW, Warner FJ, Hooper NM, Turner AJ. Membrane-associated zinc peptidase families: comparing
ACE and ACE2. Biochim Biophys Acta 2005; 1751(1): 2-8. [DOI: 10.1016/j.bbapap.2004.10.010]

15. Guy JL, Jackson RM, Acharya KR, Sturrock ED, Hooper NM, Turner AJ. Angiotensin-converting enzyme-2 (ACE2): comparative modeling of the active site, specificity requirements, and chloride dependence. Biochemistry 2003; 42(45): 13185-13192. [DOI: 10.1021/ bi035268s]

16. Cui H-T, Yu-Ting L, Li-Ying G, Xiang-Guo L, Lu-Shan $\mathrm{W}$, Jian-Wei J, et al. Traditional Chinese medicine for treatment of coronavirus disease 2019: a review. Trad Med Res 2020; 5(2): 65-73.

17. Fraga-Silva RA, Costa-Fraga FP, Murca TM, Moraes PL, Martins Lima A, Lautner RQ, et al. Angiotensinconverting enzyme 2 activation improves endothelial function. Hypertension 2013; 61(6): 1233-1238. [DOI: 10.1161/HYPERTENSIONAHA.111.00627]

18. Prada JAH, Ferreira AJ, Katovich MJ, Shenoy V, Qi $\mathrm{Y}$, Santos RAS, et al. Structure-Based Identification of Small-Molecule Angiotensin-Converting Enzyme 2 Activators as Novel Antihypertensive Agents. Hypertension 2008; 51(5): 1312-1317. [DOI: doi:10.1161/ HYPERTENSIONAHA.107.108944]

19. Velkoska E, Patel SK, Burrell LM. Angiotensin converting enzyme 2 and diminazene: role in cardiovascular and blood pressure regulation. Curr Opin Nephrol Hypert 2016; 25(5): 384-395. [DOI: 10.1097/ MNH.0000000000000254]

20. Huang L, Sexton DJ, Skogerson K, Devlin M, Smith R, Sanyal I, et al. Novel peptide inhibitors of angiotensinconverting enzyme 2. J Biol Chem 2003; 278(18): 1553215540. [DOI: 10.1074/jbc.M212934200]

21. Moccia F, Gerbino A, Lionetti V, Miragoli M, Munaron LM, Pagliaro P, et al. COVID-19-associated cardiovascular morbidity in older adults: a position paper from the Italian Society of Cardiovascular Researches. Geroscience 2020; 42(4): 1021-1049. [DOI: 10.1007/ s11357-020-00198-w]

22. Diaz JH. Hypothesis: angiotensin-converting enzyme inhibitors and angiotensin receptor blockers may increase the risk of severe COVID-19. J Travel Med 2020; 27(3): 1-2. [DOI: 10.1093/jtm/taaa041]

23. Arai T, Sekizawa K, Ohrui T, Fujiwara H, Yoshimi $\mathrm{N}$, Matsuoka $\mathrm{H}$, et al. ACE inhibitors and protection against pneumonia in elderly patients with stroke. Neurology 2005; 64(3): 573-574. [DOI: 10.1212/01. wnl.0000150897.14961.0f] 
24. Caldeira D, Alarcão J, Vaz-Carneiro A, Costa J. Risk of pneumonia associated with use of angiotensin converting enzyme inhibitors and angiotensin receptor blockers: systematic review and meta-analysis. $\mathrm{Br}$ Med $J$ 2012; 345(e4260. [DOI: 10.1136/bmj.e4260]

25. Sekizawa K, Matsui T, Nakagawa T, Nakayama K, Sasaki H. ACE inhibitors and pneumonia. Lancet 1998; 352(9133): 1069. [DOI: 10.1016/S0140-6736(05)60114-6]

26. Flacco ME, Acuti Martellucci C, Bravi F, Parruti G, Cappadona R, Mascitelli A, et al. Treatment with ACE inhibitors or ARBs and risk of severe/lethal COVID-19: a meta-analysis. Heart 2020; 106(19): 1519-1524. [DOI: 10.1136/heartjnl-2020-317336]

27. Hippisley-Cox J, Young D, Coupland C, Channon KM, Tan PS, Harrison DA, et al. Risk of severe COVID-19 disease with ACE inhibitors and angiotensin receptor blockers: cohort study including 8.3 million people. Heart 2020; 106(19): 1503-1511. [DOI: 10.1136/ heartjnl-2020-317393]

28. Guo J, Huang Z, Lin L, Lv J. Coronavirus Disease 2019 (COVID-19) and Cardiovascular Disease: A Viewpoint on the Potential Influence of Angiotensin-Converting Enzyme Inhibitors/Angiotensin Receptor Blockers on Onset and Severity of Severe Acute Respiratory Syndrome Coronavirus 2 Infection. J Am Heart Assoc 2020; 9(7): e016219. [DOI: 10.1161/JAHA.120.016219]

29. Pergolizzi JV, Varrassi G, Magnusson P, LeQuang JA, Leopoulou M, Paladini A, et al. The concern about ACE/ARB and COVID-19: Time to hold your horses! $J$ Am Pharm Ass 2020; 60(6): e88-e90. [DOI: 10.1016/j. japh.2020.06.026]

30. Rossi GP, Sanga V, Barton M. Potential harmful effects of discontinuing ACE-inhibitors and ARBs in COVID-19 patients. elife 2020; 9(e57278. [DOI: 10.7554/eLife.57278]

31. Schiffrin EL, Flack JM, Ito S, Muntner P, Webb RC. Hypertension and COVID-19. Am J Hypert 2020; 33(5): 373-374. [DOI: 10.1093/ajh/hpaa057]

32. Sommerstein R, Kochen MM, Messerli FH, Gräni C. Coronavirus Disease 2019 (COVID\&\#x2010;19): Do Angiotensin Converting Enzyme Inhibitors/Angiotensin Receptor Blockers Have a Biphasic Effect? J Am Heart Ass 2020; 9(7): e016509. [DOI: doi:10.1161/ JAHA.120.016509]

33. South AM, Tomlinson L, Edmonston D, Hiremath S, Sparks MA. Controversies of renin-angiotensin system inhibition during the COVID-19 pandemic. Nat Rev Nephrol 2020; 16(6): 305-307. [DOI: 10.1038/s41581020-0279-4]

34. Sriram K, Insel PA. Risks of ACE Inhibitor and ARB Usage in COVID-19: Evaluating the Evidence. Clin Pharmacol Ther 2020; 108(2): 236-241. [DOI: 10.1002/ cpt.1863]

35. Tetlow S, Segiet-Swiecicka A, O’Sullivan R, O'Halloran $\mathrm{S}$, Kalb K, Brathwaite-Shirley C, et al. ACE-Inhibitors, Angiotensin Receptor Blockers and Endothelial Injury in COVID-19. J Intern Med 2020. [DOI: 10.1111/ joim.13202]

36. Vaduganathan M, Vardeny O, Michel T, McMurray JJV, Pfeffer MA, Solomon SD. Renin-AngiotensinAldosterone System Inhibitors in Patients with Covid-19. N Engl J Med 2020; 382(17): 1653-1659. [DOI: 10.1056/ NEJMsr2005760]

37. Wang JJ, Edin ML, Zeldin DC, Li C, Wang DW, Chen C. Good or bad: Application of RAAS inhibitors in COVID-19 patients with cardiovascular comorbidities. Pharmacol Ther 2020; 215(107628. [DOI: 10.1016/j. pharmthera.2020.107628]

38. Wang K, Gheblawi M, Oudit GY. Angiotensin Converting Enzyme 2: A Double-Edged Sword. Circulation 2020. [DOI: 10.1161/CIRCULATIONAHA.120.047049]

39. Zhang $\mathrm{P}$, Zhu L, Cai J, Lei F, Qin J-J, Xie J, et al. Association of Inpatient Use of Angiotensin-Converting Enzyme Inhibitors and Angiotensin II Receptor Blockers With Mortality Among Patients With Hypertension Hospitalized With COVID-19. Circ Res 2020; 126(12): 1671-1681. [DOI: 10.1161/CIRCRESAHA.120.317134]

40. Leclézio A, Robinso J, Banerjee I. SARS-CoV-2: ACE inhibitors, disastrous or desirable? J Biomed Sci 2020; 7(1): 40-46. [DOI: 10.3126/jbs.v7i1.29852]

41. Koshy AN, Murphy AC, Farouque O, Ramchand J, Burrell LM, Yudi MB. Renin-angiotensin system inhibition and risk of infection and mortality in COVID-19: a systematic review and meta-analysis. Intern Med J 2020; 1-7. [DOI: 10.1111/imj.15002]

42. Battistoni A, Volpe M. Might renin-angiotensin system blockers play a role in the COVID-19 pandemic? Eur Heart J Cardiovasc Pharmacother 2020; 6(4): 248-251. [DOI: 10.1093/ehjcvp/pvaa030]

43. Froldi G. What could be the better choice between ACE inhibitors and AT1R antagonists in coronavirus disease 2019 (COVID-19) patients? J Med Virol 2020; 92(11): 2302-2303. [DOI: 10.1002/jmv.25974] 
44. Messerli FH, Siontis GCM, Rexhaj E. COVID-19 and Renin Angiotensin Blockers: Current Evidence and Recommendations. Circulation 2020; 141(25): 20422044. [DOI: 10.1161/CIRCULATIONAHA.120.047022]

45. Aitken RJ. COVID-19 and human spermatozoaPotential risks for infertility and sexual transmission? Andrology 2020; n/a(n/a): 1-5. [DOI: 10.1111/ andr.12859]

46. Anifandis G, Messini CI, Daponte A, Messinis IE. COVID-19 and fertility: a virtual reality. Reprod BioMed Online 2020; 41(2): 157-159. [DOI: 10.1016/j. rbmo.2020.05.001]

47. Ojaghi M, Kastelic J, Thundathil J. Testis-specific isoform of angiotensin-converting enzyme (tACE) is involved in the regulation of bovine sperm capacitation. Mol Reprod Dev 2017; 84(5): 376-388. [DOI: doi:10.1002/ $\operatorname{mrd} .22790]$

48. Gianzo M, Urizar-Arenaza I, Muñoa-Hoyos I, Larreategui
Z, Garrido N, Casis L, et al. Human sperm testicular angiotensin-converting enzyme helps determine human embryo quality. Asian J Androl 2018; 20(5): 498-504. [DOI: 10.4103/aja.aja_25_18]

49. Foresta C, Rocca MS, Di Nisio A. Gender susceptibility to COVID-19: a review of the putative role of sex hormones and X chromosome. $J$ Endocrinol Invest 2020. [DOI: 10.1007/s40618-020-01383-6]

50. Wang Z, Xu X. scRNA-seq Profiling of Human Testes Reveals the Presence of the ACE2 Receptor, A Target for SARS-CoV-2 Infection in Spermatogonia, Leydig and Sertoli Cells. Cells 2020; 9(4). [DOI: 10.3390/ cells9040920]

51. Reis FM, Bouissou DR, Pereira VM, Camargos AF, dos Reis AM, Santos RA. Angiotensin-(1-7), its receptor Mas, and the angiotensin-converting enzyme type 2 are expressed in the human ovary. Fert Steril 2011; 95(1): 176-181. [DOI: 10.1016/j.fertnstert.2010.06.060] 